\title{
Investigation of the Effect of Cycling on the Performance of Packed Bed Solar Energy Storage System
}

\author{
Lokesh Pandey $^{1}$, Ajay Dobhal ${ }^{2}$ and Amrish Joshi ${ }^{3}$ \\ DIET, Rishikhesh1, JBIT Dehradun2,Student DIT Dehradun3 \\ lokesh.pandey21@gmail.com
}

\begin{abstract}
Packed bed thermal energy storage system is an important component of solar energy conversion system. Conventionally packed bed systems have been designed on the basis of the thermal energy considerations only. Charging and then discharging of bed complete one cycle. It has now been realized that in cycling process special attention needs to be paid to the design to take into account the energy losses as well as the maximum utilization of available energy. In this work, an investigation has been carried out on the effect of cycling (charging and discharging cycle) on the performance of packed bed solar energy storage system. Temperature profiles during charging and discharging have been determined. It has been found that during finite time discharging, the bed cannot be fully discharged and certain amount of unused energy still remains entrapped in the bed. Stabilized unused energy has been found which has been seen to be strongly affected by the bed parameters, namely, the element size and shape, void fraction and aspect ratio of the bed. The values of these parameters to result in minimum value of this stabilized unused energy have been found within the range of investigation. It has been found that unused energy can be minimized by keeping element size to be small and by using highly non spherical elements combined by high void fraction and large aspect ratio of the bed.
\end{abstract}

\section{Introduction}

In view of the growing energy demand and the increasing environmental concerns alternatives to the use of conventional and highly polluting fossil fuel energy resources have to be urgently found. Solar energy is considered to be the most important and viable alternative renewable energy resource due to its quantitative abundance. Although solar energy is available everywhere but its availability is highly intermittent. It is therefore necessary to provide a suitable storage system with solar energy collectors to store energy to meet the demand in the absence of solar radiation availability. In the case of solar air heating application, packed bed generally represents the most suitable energy storage unit as mentioned by Cautier and Farber[4]. During charging mode,solar heated air is forced into the top of the container i.e. upper plenum and then passes evenly through the bed, heating the storage element and passes out through the lower plenum. Air is drawn off at the bottom and returned to the solar collector for heating again as shown in Figure1 


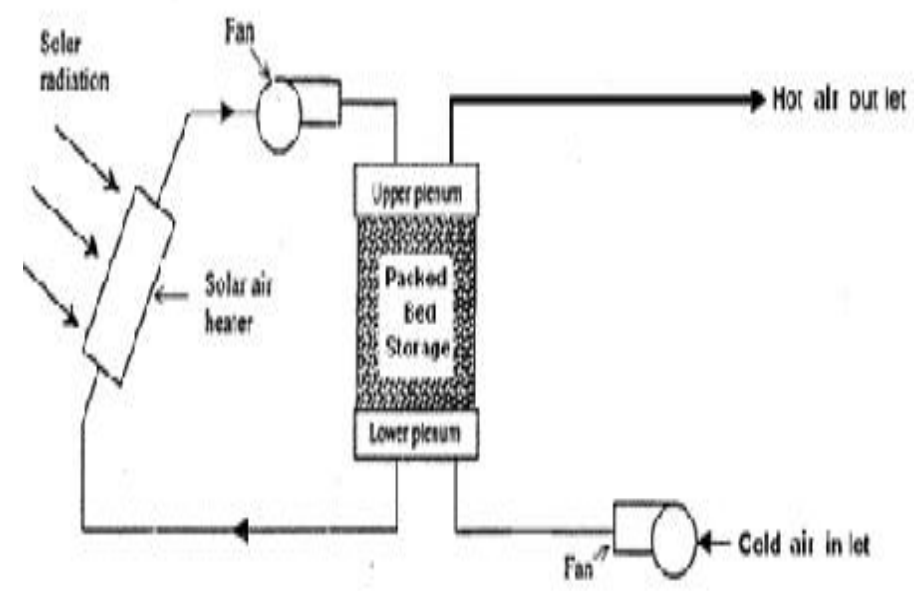

Figure 1.Basic Arrangement of Packed Bed Storage System

The energy stored during charging is usually not completely withdrawn in the finite time interval resulting in some unused energy that is not recovered during one complete charging - discharging cycle. The amount of unused energy is a function of system (element size, void fraction, element shape, aspect ratio) and operating parameters. This unused energy is likely to change on next cycle of operation because of different initial conditions for each cycle. The conditions stabilized as the charging - discharging cycles are repeated. This stabilized value of unused energy will be function of system and operating parameters as also the number of cycles of operation. A good design of the storage system should yield minimum value of this stabilized unused energy which will result from an optimum set of values of system and operating parameters.

\section{Analysis of Packed Bed Solar Thermal Energy}

Mumma and Marvin[11] simulation method for thermal behavior of the packed bed during storage as well as withdrawal phase has been used to predict the temperature profiles of the bed as well as air. The prediction procedure requires a number of assumptions as also the values of fixed and variable system parameters.

\section{ASSUMPTIONS MADE IN THE ANALYSIS}

The analysis of the system described in the present study is based on the following assumptions:

a) There is no vaporization or condensation.

b) The same kind of gas flows through the sensible heat storage bed in both the storage and removal processes. This gas is an ideal gas with a constant specific heat.

c) All storage bed elements are of the same shape and the bed is homogeneous.

d) Thermo-physical properties of gas as well as bed material are independent of temperature.

e) Heat transfer is one dimensional. 


\section{RANGE OF PARAMETERS}

As discussed above, the system parameters considered in the present study are sphericity $(\Psi)$ of the material elements, void fraction $(\varepsilon)$, and equivalent diameter of the bed element (De) and aspect ratio of bed (L/D). The range of these parameters selected for the investigation is given in Table 1.

Table 1

\begin{tabular}{|c|c|}
\hline Parameter & Range \\
\hline 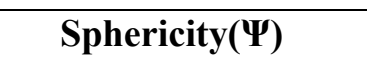 & $0.5-1$ \\
\hline Void fraction(z) & 0.3-0.5 \\
\hline $\begin{array}{c}\text { Equivalent } \\
\text { diameter,De(m) }\end{array}$ & $.05-0.2$ \\
\hline Aspect Ratio(L/D) & $1-5$ \\
\hline
\end{tabular}

\section{Values of Fixed Parameters}

Table 2

\begin{tabular}{|c|c|c|c|}
\hline $\begin{array}{l}S \\
\text { No. }\end{array}$ & Description & $\begin{array}{l}\text { Para } \\
\text { meter }\end{array}$ & Value \\
\hline 1 & $\begin{array}{l}\text { Volume of packed bed } \\
\left(\mathrm{m}^{3}\right)\end{array}$ & $\left(\mathrm{V}_{\mathrm{b}}\right)$ & 18 \\
\hline 2 & Insolation $\left(\mathrm{W} / \mathrm{m}^{2}\right)$ & (I) & 500 \\
\hline 3 & Number of bed element & $(\mathrm{N})$ & 60 \\
\hline 4 & $\begin{array}{l}\text { Initial bed temperature } \\
\left({ }^{0} \mathrm{C}\right)\end{array}$ & $\left(\mathrm{T}_{\mathrm{bi}}\right)$ & 25 \\
\hline 5 & Density of air, $\mathrm{kg} / \mathrm{m}^{3}$ & $\left(\rho_{\mathrm{a}}\right)$ & 1.1 \\
\hline 6 & $\begin{array}{l}\text { Dynamic viscosity of } \\
\text { air, kg/s-m }\end{array}$ & $\left(\mu_{\mathrm{a}}\right)$ & $1.865 \times 10^{-5}$ \\
\hline 7 & ${ }^{0} \mathrm{C}$ Ambient temperature, & $\mathrm{T}_{\infty}$ & 25 \\
\hline 8 & $\begin{array}{cc}\text { Density of } & \text { storage } \\
\text { material, }\left(\mathrm{kg} / \mathrm{m}^{3}\right) & \end{array}$ & $\rho_{\mathrm{s}}$ & 1920 \\
\hline 9 & $\begin{array}{l}\text { Specific heat of air, } \\
\left(\mathrm{J} / \mathrm{kg}^{0} \mathrm{C}\right)\end{array}$ & $\mathrm{C}_{\mathrm{pa}}$ & 1008 \\
\hline $0^{1}$ & $\begin{array}{l}\text { Specific heat of storage } \\
\text { material, }\left(\mathrm{J} / \mathrm{kg}^{0} \mathrm{C}\right)\end{array}$ & $\mathrm{C}_{\mathrm{ps}}$ & 835 \\
\hline 11 & Collector area, $\mathrm{m}^{2}$ & $\mathrm{~A}_{\mathrm{c}}$ & 20 \\
\hline
\end{tabular}




\begin{tabular}{|c|c|c|c|}
\hline $2^{1}$ & (for collector) & $\alpha)_{\mathrm{e}}{ }^{F_{R}(\tau}$ & 0.62 \\
\hline $3^{1}$ & (for collector) & $\mathrm{F}_{\mathrm{R}} \mathrm{U}_{1}$ & 3.38 \\
\hline $4^{1}$ & Time interval,(minutes) & $\Delta \mathrm{t}$ & 1 \\
\hline
\end{tabular}

Table-2 lists the values of fixed parameters which are required to simulate the system performance, the specification of the collector system, storage dimensions and their related parameters, thermo physical properties, ambient and initial temperature.

\section{PROCEDURE OF PREDICTION OF PERFORMANCE}

Using the mathematical model for predicting the performance of the system a step by step procedure has been developed with the objective of obtaining the values of the following parameters during charging and discharging process.

(i) Mass flow rate of air

(ii) Volumetric heat transfer coefficient,

(iii) Temperature of air at the outlet of each element of the bed.

(iv) Mean temperature of each element of the bed.

(v) Mean temperature of bed after charging.

(vi) Mean temperature of bed after discharging.

(vii) Stabilized unused energy remaining in bed after discharging

Values of the above mentioned parameters has been determined as functions of system parameters, namely equivalent diameter(De), void fraction $(€)$, sphericity $(\Psi)$ and aspect ratio $(\mathrm{L} / \mathrm{D})$.

The calculation starts with fixed values of parameters $\left(F_{R}(\tau \alpha)_{e}, F_{R} U_{1}\right.$ and $\left.I\right)$ and proceeds with the calculation of other parameters for obtaining cycle stabilization unused energy. For this purpose a step by step procedure is given below:

1. A set of the values of the parameters namely void fraction, sphericity ,equivalent diameter and aspect ratio as per the geometry used is selected for which the calculation is to be performed.

2. Values of fixed parameters namely insolation $\left(\mathrm{I}=500 \mathrm{~W} / \mathrm{m}^{2}\right.$, initial bed temperature $\left(\mathrm{T}_{\mathrm{bi}}=25^{\circ} \mathrm{C}\right)$ etc. are taken.

3. Useful heat gain by collector is calculated by using Hottel and Whillier[10] energy balance equation,

$$
\mathrm{Q}_{\mathrm{u}}=\mathrm{A}_{\mathrm{c}} \times\left[\left(\mathrm{F}_{\mathrm{R}}(\tau \alpha)_{\mathrm{e}} \times \mathrm{I}\right)-\mathrm{F}_{\mathrm{R}} \mathrm{U}_{\mathrm{l}}\left(\mathrm{T}_{\mathrm{ic}}-\mathrm{T}_{\mathrm{amb}}\right)\right]
$$

The term $(\tau \alpha)_{\mathrm{e}}$ represents effective transmittance-absorptance product, $\mathrm{U}_{1}$ is overall heat loss coefficient $\left(\mathrm{W} / \mathrm{m}^{20} \mathrm{C}\right)$ and $\mathrm{F}_{\mathrm{R}}$ is the heat removal factor defined as ratio of actual useful energy gain to the maximum possible energy gain.

here $T_{i c}$ is the outlet temperature of the air from the packed bed and is equal to $T_{A 60}$ (temperature of the air leaving $60^{\text {th }}$ element of the bed). For time instant $t=0$, this temperature is assumed to be same as initial temperature of bed.

4.

$m_{a}=Q_{u} / C_{p a}\left(T_{i b}-T_{i c}\right)$

temperature and

5.
Mass flow rate of air is calculated as,

where, $\mathrm{T}_{\mathrm{ib}}$ is inlet to bed $\mathrm{T}_{\text {ic }}$ is the outlet temperature of bed.

Reynolds number is calculated by: 
$\mathrm{Re}=\mathrm{G} \times \mathrm{D}_{\mathrm{e}} / \mu_{\mathrm{a}}$

$$
\text { where, } \mathrm{G} \text { is mass velocity and calculated by; }
$$

6. Volumetric heat transfer coefficient is calculated by using the expression given by Chandra and Willits [5] for convection mode of heat transfer in packed bed. Nusselt number for a packed bed in modified form as:

$$
N u=\frac{h_{v} D_{e}^{2}}{k_{a}}
$$

for Nusselt number in terms is given by Singh,

The correlation

\section{Ranjit[15]}

$$
N_{u}=0.437 \times R_{e}^{0.75} \times \psi^{3.35} \times \varepsilon^{-1.62}\left\{\exp \left[29.03(\log \psi)^{2}\right]\right\}
$$

Thus the expression for volumetric heat transfer coefficient is:

$$
h_{v}=\frac{\left(k_{a}\left[0.437 \times R_{e}{ }^{0.75} \times \psi^{3.35} \times \varepsilon^{-1.62}\left\{\exp \left[29.03(\log \psi)^{2}\right]\right\}\right]\right)}{\left(D_{e}{ }^{2}\right)}
$$

7. The following relation is used to find the temperature of the air ' $\mathrm{T}_{\mathrm{a}, \mathrm{m}+1}$ ' at the exit of $m$ element.

$T_{a, m+1}=T_{b, m}+\left(T_{a, m}-T_{b, m}\right) \exp \left(-\Phi_{1}\right)$

Where, $\Phi_{1}=\frac{\mathrm{NTU}}{\mathrm{N}}$ and

NTU (number of transfer unit) $=\frac{h_{v} A_{b} L}{\left(\dot{\mathrm{m}} m C_{p}\right)_{a}}$

here, $A_{b}=$ cross sectional area of packed bed.

$L=$ is length of packed bed,

$N=$ is number of bed elements,

$h_{v}=$ Volumetric heat transfer coefficient.

8. Temperature of $\mathrm{m}$ bed element calculated as follows:

$$
T_{b, m(t+\Delta t)}=T_{b, m(t)+}+\left[\Phi_{2}\left(T_{a, m}-T_{a, m+1}\right)\right] \Delta t
$$

where, $\Phi_{2}=\frac{\left(m \mathrm{C}_{\mathrm{p}}\right)_{\mathrm{a}} \mathrm{N}}{\left(\rho \mathrm{C}_{\mathrm{p}}\right)_{\mathrm{s}} \mathrm{AL}(1-\epsilon)}$

and $\Delta \mathrm{t}$ is time increment.

9. Calculation of temperature of air coming out from each element $\mathrm{T}_{\mathrm{a}}(\mathrm{m}+1)$ and temperature of each bed

element $T_{b, m}$ are thus calculated for given instant of time for all elements $m=1,60$ usinf steps 7 and 8 . 
10. These calculation are then repeated for all instants of time $\mathrm{t}=0,8 \mathrm{hrs}$. This refers to charging for day 1 .

11. Temperature distribution of bed at $\mathrm{t}=8 \mathrm{hrs}$ is then used as initial condition for discharging process.

12. Using a fixed flow rate of air $m_{c}=Q_{h} /\left(C_{p a}\left(T_{\text {Load }}-T_{a m b}\right) \times 8 \times 60 \times 60\right)$

and inlet temperature of ambient condition, the calculations of steps 9 and 10 are repeated using $m=60$ as $m=1$ and vice versa i.e as $m=1$ as $m=60$. This refers to discharging for day 1.

13. Temperature distribution of bed at the end of discharging process is then used as initial condition for bed temperature for calculation of temperature distribution of charging for day 2 and so on.

14. Mean bed temperature calculated at the end of cycle 1 (charging day $1+$ discharging day 1) is compared with mean bed temperature calculated at the end of cycle 2 (charging day $2+$ discharging day 2 ). If the difference between these two temperature is more than $0.2 \%$, the calculation of steps 7 to 13 are reapeted for cycle 3 otherwise it is terminated. On termination the value of unused energy is calculated as

$$
\mathrm{Q}=\left(\rho \mathrm{C}_{\mathrm{p}}\right)_{\mathrm{s}}(1-\epsilon) \mathrm{V}\left(\mathrm{T}_{\mathrm{bm}}-\mathrm{T}_{\mathrm{amb}}\right)
$$

where $_{\mathrm{bm}}$ is the mean bed temperature at the end of the cycle when calculation is terminated.

15. Above mentioned calculation procedure (step 1 to step 14) is repeated for different sets of values of system parameters, namely equivalent diameter (De), Void fraction (C), Sphericity ( $\Psi$ ) and aspect ratio (L/D). (in all $5 \times 5 \times 5 \times 5=625$ sets of calculation)

\section{Result and Discussion}

Figure 2 to Figure 5show the temperature distribution of bed during charging and discharging. Figure 2 shows the temperature profiles during charging for a typical set of values of system parameters $(\mathrm{De}=0.05, \mathrm{C}=0.5, \Psi=0.75, \mathrm{~L} / \mathrm{D}=3$ ). It can be seen that the temperature rises from an initial temperature of $298 \mathrm{~K}$, gradually to attain a mean temperature close to $313 \mathrm{~K}$ during a period of 8 hours. During discharging as shown in Figure 3, similar changes in temperature can be observed and finally the mean bed temperature attains a value close to $298 \mathrm{~K}$, but not equal to $298 \mathrm{~K}$ as it ideally should be. This is the limitation of such systems because; the heat transfer rate attains a very low value due to very small temperature differential towards the end of charging/discharging period. This is the time when the entire bed has attained a temperature quite close to fluid temperature and hence heat transfer is very low. The energy represented by the temperature profile of the bed at the end of discharging is unused energy which cannot be recovered under normal operation of the system. Similar Figure 4 and Figure 5 showing the temperature profile for second cycle of operation reveal an important characteristics difference. Figure 4 shows that towards the end of charging, almost the entire bed has attained a temperature close to $313 \mathrm{~K}$ whereas Figure 5 still reveals a substantially high average bed temperature at the end of discharging. The unused energy represented by second cycle can be assumed as "stabilized unused energy" which in this case amounts to 17.6 MJ. 


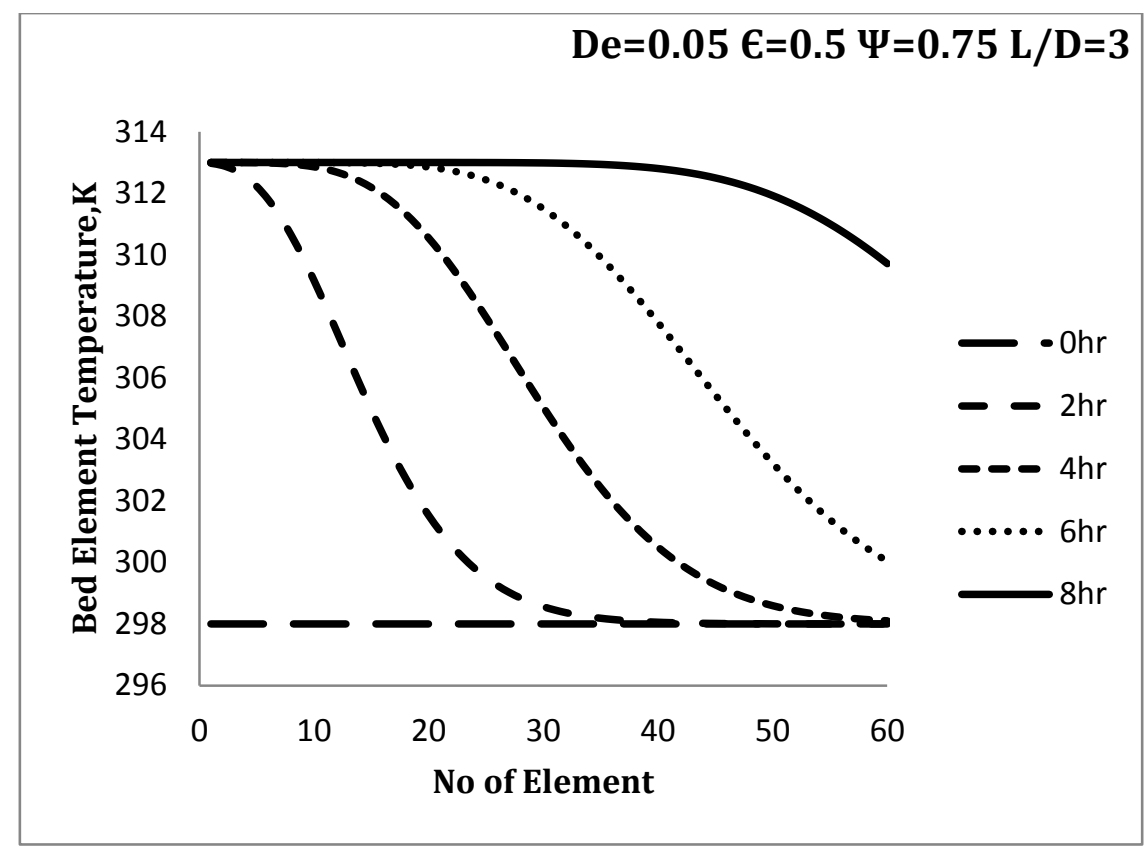

Figure 2. Temperature Distribution of Bed During Charging for Day1

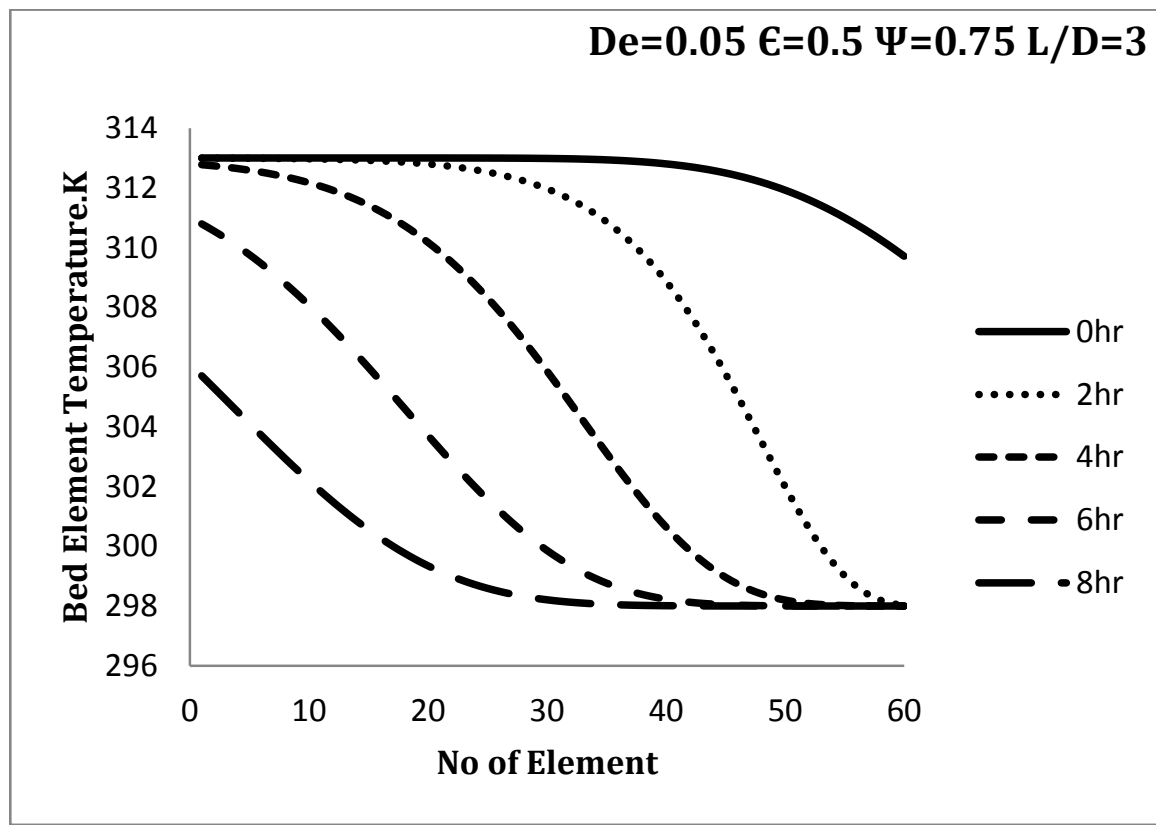

Figure 3. Temperature Distribution of Bed During Discharging for Day 1 


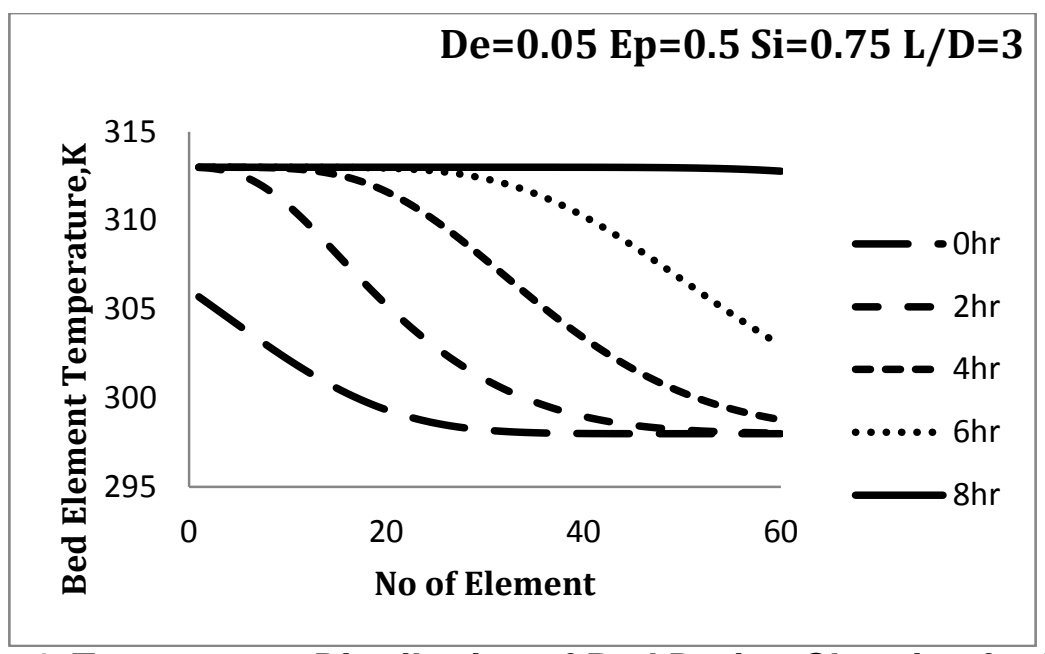

Figure 4. Temperature Distribution of Bed During Charging for Day 2

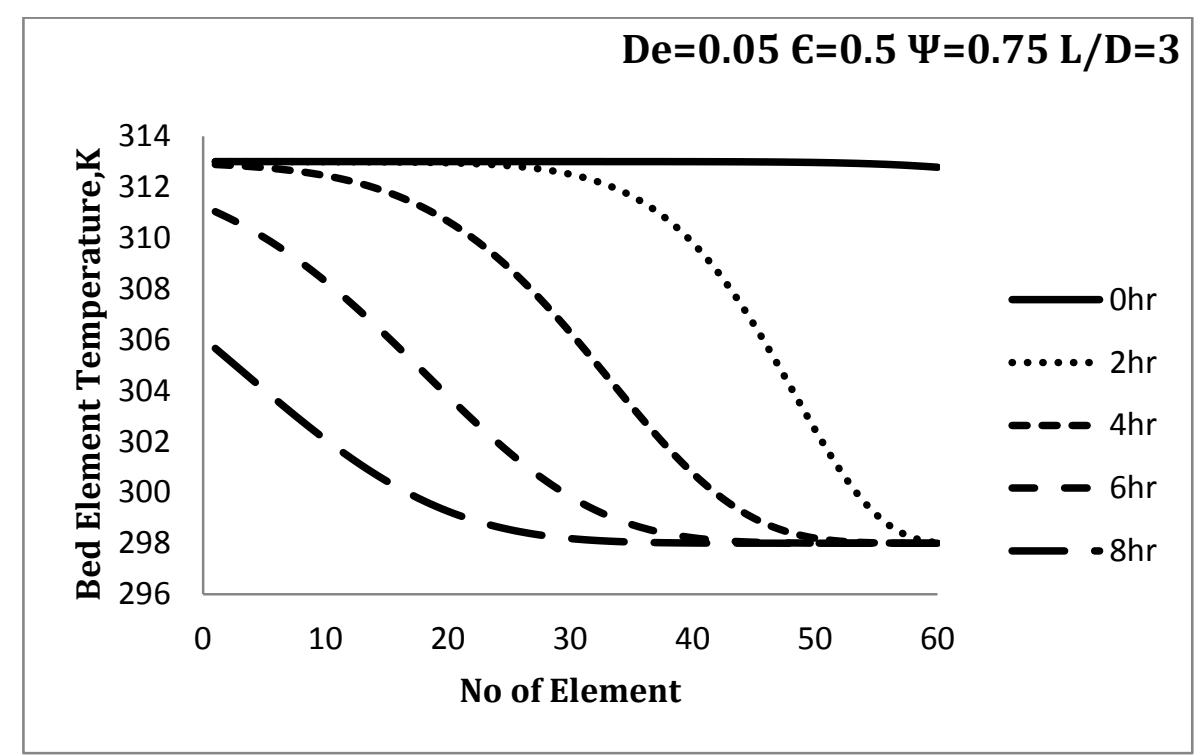

Figure 5. Temperature Distribution of Bed During Discharging for Day 2 


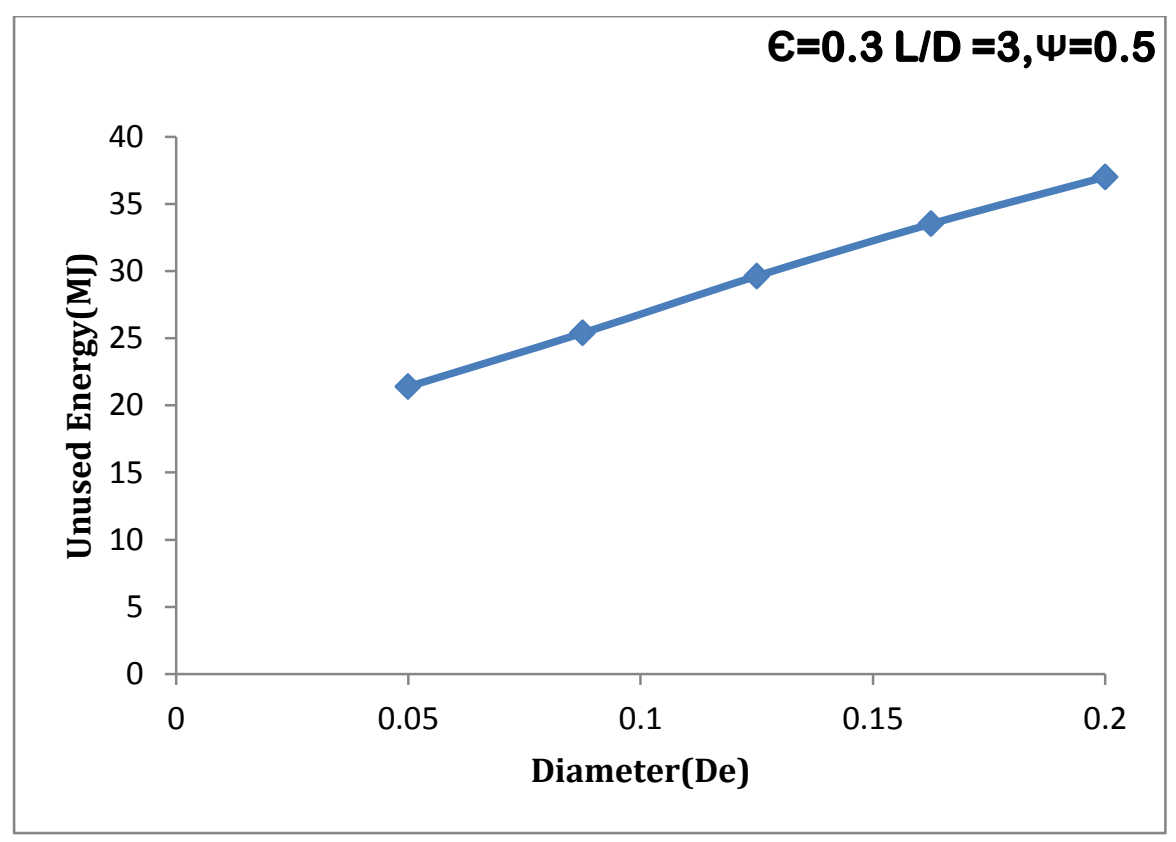

Figure 6. Distribution of Unused Energy with Respect to Equivalent Diameter

Figure6 shows that effect of equivalent diameter of bed element on the value of stabilized unused energy. It can be seen from Figure6 that the unused energy increases from a low value to higher value as the diameter increases. This is may be due to the fact that higher diameter results in poorer heat transfer conditions and hence a poorer withdrawal of energy during given period of time.

It has been stated (Ranjitsingh [15] ) that there exists a value of sphericity for minimum heat transfer coefficient, an increasing value decreases the heat transfer coefficient attaining a minima for a value of 0.75 and then increasing with further increase of sphericity. This is also reflected in Figs. 7 where it is seen that the unused energy attains a maxima corrospoding to this value of sphericity for given set of system parameters. Value of unused energy increases with an increase of sphericity, attaining a maxima for a sphericity of 0.75 and then decreasing as the sphericity is increased.

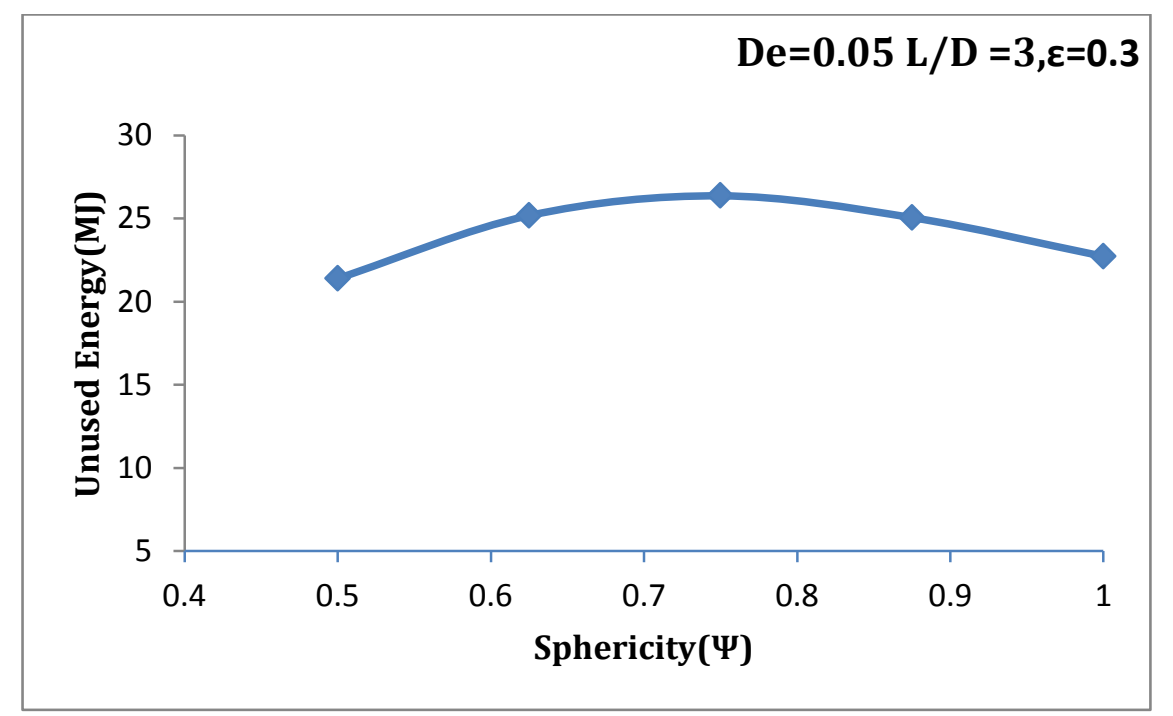

Figure 7. Distribution of Unused Energy with Respect to Sphericity 


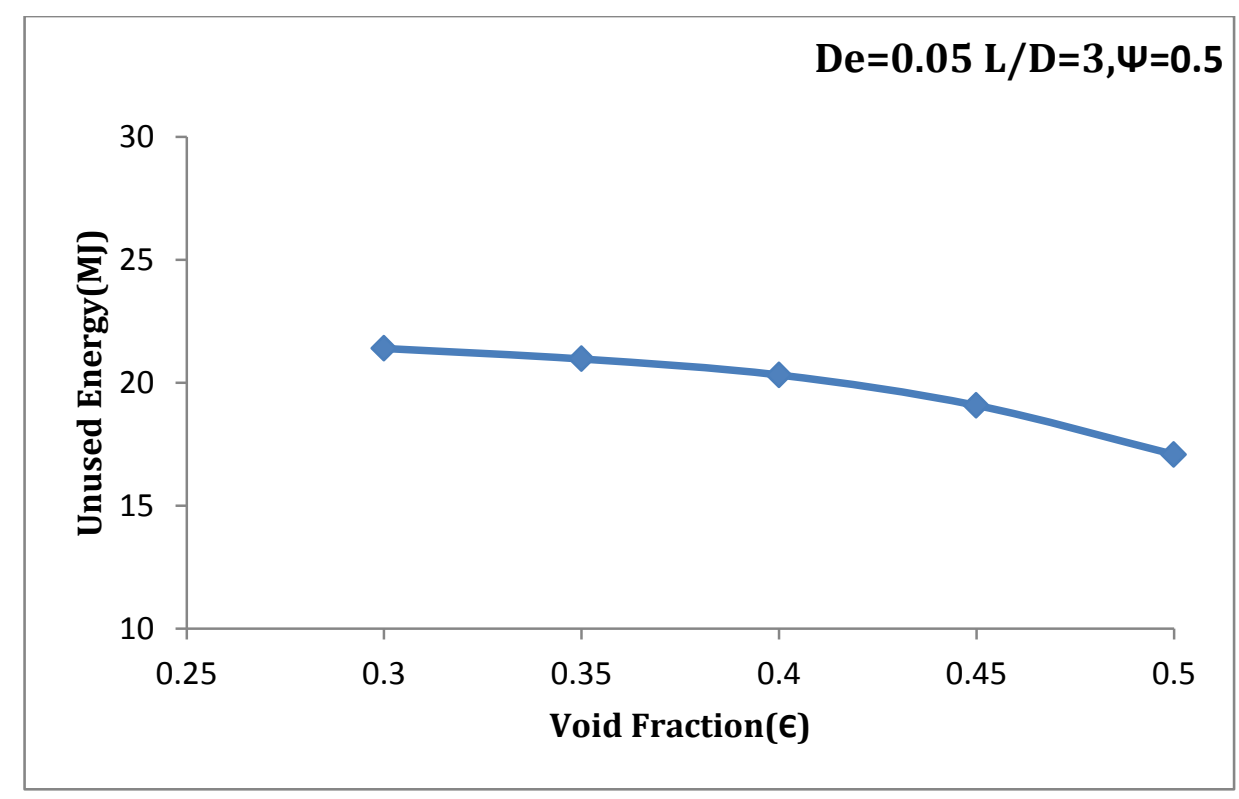

Figure 8. Distribution of Unused Energy with Respect to Void Fraction

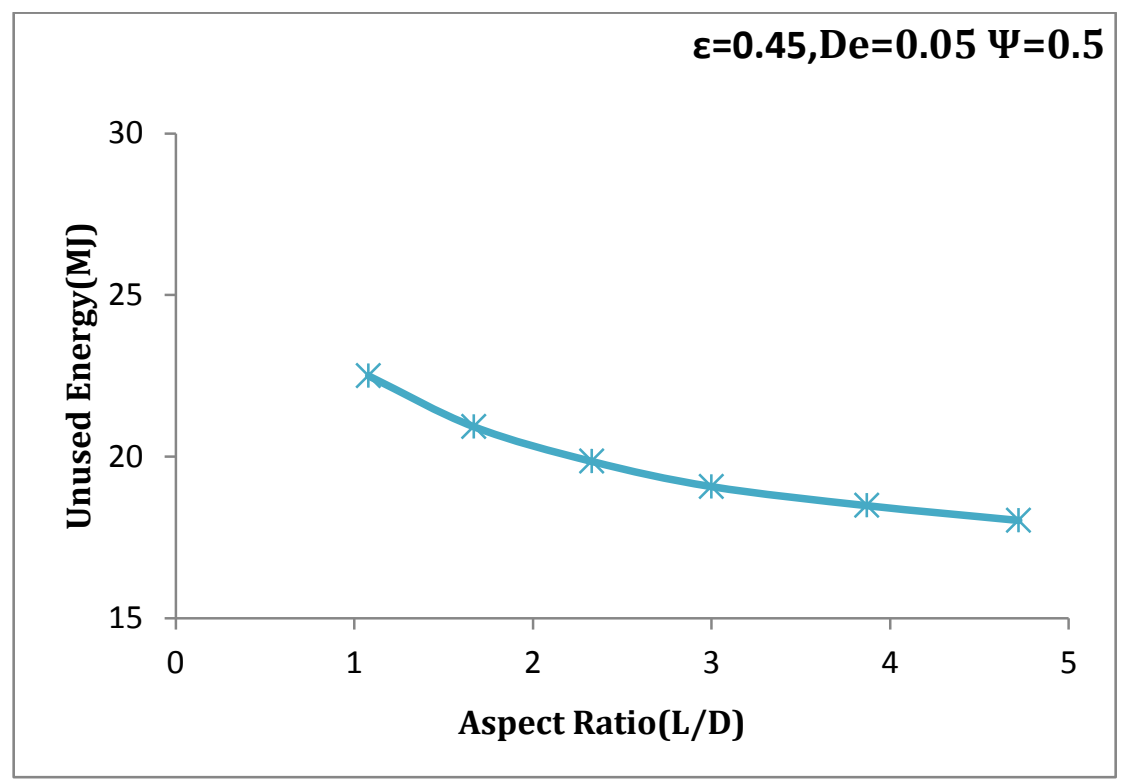

Figure 9. Distribution of Unused Energy with Respect to Aspect Ratio

Figure 8 show that the value of stabilized unused energy is a function of void fraction, the value slightly increases as the void fraction is increased, attains a maxima and then decreasing to a minimum value as the void fraction is increased to the maximum value of 0.5 investigated in this work.

Figure 9 Show the effect of variation of "aspect ratio" on the value of stabilized unused energy of the storage considered. It is seen that in all cases the value of stabilized unused energy decreases with an increase of aspect ratio, the highest aspect ratio of 5 representing the optimum condition. This seems to happen due to high heat transfer coefficient values attained when the length to diameter ratio of the bed is high. A higher value of this ratio represents a smaller flow cross-section for a given bed volume and flow rate. A higher velocity and hence a higher turbulence results in higher heat transfer coefficient. 


\section{Conclusion}

Based on this work, following major conclusions have been drawn.

1. It is observed from temperature distribution in bed that the temperature both during charging and discharging is strong function of element size, void fraction, shape and aspect ratio of bed.

2. It is observed that bed with elements having sphericity of 0.5 is most stratified during charging.

3. The mean bed temperature is found to decrease with increase in equivalent diameter of element during charging and during discharging the mean bed temperature increases with increase in equivalent diameter of bed elements.

4. It is observed that the bed with elements of sphericity of 0.75 has the maximum stabilized unused energy during cyclic process whereas bed elements of sphericity of 0.50 are seen have minimum unused energy.

5. It is observed that the unused energy is found to increase with increase in equivalent diameter of bed element.

6. The unused energy is found to decrease with increase in void fraction of bed.

7. It is observed that the unused energy decreases with increase in aspect ratio of bed.

8. Stabilized unused energy is minimum for minimum equivalent diameter of bed elements, highly non-spherical elements, highest void fraction of bed and highest aspect ratio of bed.

Summarizing, it is observed that the bed (system) parameters strongly affect the performance of the bed and the stabilized unused energy can be minimized by keeping smaller element size, using non-spherical elements and making the bed to have high void fraction and high aspect ratio.

\section{$\underline{\text { Appendix }}$}

\begin{tabular}{|c|c|}
\hline$A_{b}$ & Cross sectional area of packed bed, $\mathrm{m}^{2}$ \\
\hline$A_{c}$ & Collector area, $\mathrm{m}^{2}$ \\
\hline $\mathrm{C}_{\mathrm{p}}$ & Specific heat, $\mathrm{J} \mathrm{kg}^{-1} \mathrm{~K}^{-1}$ \\
\hline $\mathrm{D}_{\mathrm{e}}$ & Equivalent diameter of material particle, $\mathrm{m}$ \\
\hline $\mathrm{f}$ & Friction factor, dimensionless \\
\hline G & Mass velocity of air, $\mathrm{kg} \mathrm{s}^{-1} \mathrm{~m}^{-2}$ \\
\hline $\mathrm{h}$ & Heat transfer coefficient, $\mathrm{Wm}^{-2} \mathrm{~K}^{-1}$ \\
\hline$h_{v}$ & Volumetric heat transfer coefficient, $\mathrm{Wm}^{-3} \mathrm{~K}^{-1}$ \\
\hline I & Insolation, $\mathrm{W} \mathrm{m}^{-2}$ \\
\hline $\mathrm{I}_{\mathrm{sc}}^{\prime}$ & Actual value of solar constant, $\mathrm{W} \mathrm{m}^{-2}$ \\
\hline $\mathrm{k}$ & Thermal conductivity, $\mathrm{Wm}^{-1} \mathrm{~K}^{-1}$ \\
\hline $\mathrm{L}$ & Length or height of the bed, $\mathrm{m}$ \\
\hline $\mathrm{L} / \mathrm{D}$ & Aspect Ratio, \\
\hline$\dot{m}$ & Mass flow rate, $\mathrm{kg} \mathrm{s}^{-1}$ \\
\hline $\mathrm{N}$ & Number of bed elements, dimensionless \\
\hline NTU & Number of transfer units, dimensionless \\
\hline$\Delta \mathrm{P}$ & Pressure drop across the bed, $\mathrm{Nm}^{-2}$ \\
\hline $\mathrm{Q}_{\mathrm{h}}$ & Thermal energy stored in the bed during charging, J \\
\hline $\mathrm{Q}_{\mathrm{c}}$ & Available energy stored in the bed during discharging, $\mathrm{J}$ \\
\hline $\mathrm{Q}_{\mathrm{u}}$ & Useful energy gain in the collector, $\mathrm{W}$ \\
\hline $\mathrm{Q}$ & Stabilized unused energy, $\mathrm{J}$ \\
\hline q & Rate of heat transfer or rate of heat storage, $\mathrm{W}$ \\
\hline
\end{tabular}




$\begin{array}{ll}\mathrm{Re} & \text { Reynolds number, dimensionless } \\ \mathrm{T}_{\infty} & \text { Ambient temperature, }{ }^{\circ} \mathrm{C}(\mathrm{K}) \\ \mathrm{T}_{\mathrm{a}} & \text { Temperature of air in the bed, }{ }^{\circ} \mathrm{C}(\mathrm{K}) \\ \mathrm{T}_{\mathrm{bi}} & \text { Inlet temperature to the bed, }{ }^{\circ} \mathrm{C}(\mathrm{K}) \\ \Delta \mathrm{t} & \text { Time interval, } \mathrm{s} \\ \mathrm{T}_{\mathrm{bm}} & \text { Average/mean temperature of bed, }{ }^{\circ} \mathrm{C}(\mathrm{K}) \\ \mathrm{T}_{\mathrm{ib}} & \text { Initial temperature of bed, }{ }^{\circ} \mathrm{C}(\mathrm{K}) \\ \mathrm{T}_{\mathrm{ic}} & \text { Temperature of fluid at bed outlet, }{ }^{\circ} \mathrm{C}(\mathrm{K}) \\ \mathrm{t}_{\mathrm{ch}} & \text { Charging time, } \mathrm{s} \\ \mathrm{V}_{\mathrm{b}} & \text { Volume of packed bed, } \mathrm{m}^{3} \\ \mathrm{x} & \text { Distance along the bed, } \mathrm{m}\end{array}$

\section{References}

[1] Balakrishnan, Arcot R. and Pei, David C.T., "Heat Transfer in Packed Bed Systems-A Critical Review", Ind. Engg. Chem. (Process Des. Dev.) Vol. 30-40, 1979-a.

[2] Bejan,A." Two thermodynamic optima in the design of sensible heat units for energy storage",J.Heat transfer 100,708-712( 1978).

[3] Bouwman, A.M., Bosman, J.C., Vonk, P., Wesselingh, J.A. and Frijlink, H.W., "Which Shape Factor(s) Best Describe Granules?", Powder Technology, Vol. 146, 66-72, 2004.

[4] Cautier, J. Pascal, and Farber, E.A., "Two Applications of a NumericalApproach of Heat Transfer Process within Rock Beds", Solar Energy, Vol. 29(6), 45 1-462, 1982.

[5] Chandra, Pitam and Willits, D.H., "Pressure Drop and Heat Transfer Characteristics of Air Rock Bed Thermal Storage Systems", Solar Energy, Vol. 27(6), 547-553, 1981.

[6] Duffie, John A. and Beckman, William A., "Solar Engineering of Thermal Processes" $2{ }^{\text {nd }}$ Edition, John Wiley \& Sons Inc., 1991.

[7] Dunkle, R.V. and Ellul, W.M.J., "Randomly Packed Particulate Bed Regenerators and Evaporative Coolers" Mech. and Chem. Engg. Trans., Inst. Engrs., Australia, Vol. MC8, 117-122, 1972.

[8] Elsari, M. and Hughes, R., "Axial Thermal Conductivities of Packed Beds", Applied Thermal Engg., Vol. 22, 1969-1980, 2002.

[9] Ergun, S., "Fluid Flow Through Packed Columns", Chemical Engg. Science, Vol.48 (2), 89-94, 1951.

[10] Hottel, H.C. and Whillier, A., "Evaluation of Flat Plate Collector Performance", Trans. of the Conference on the Use of Solar Energy, University of Arizona Press, Vol. 2, 74-104, 1958.

[11] Mumma, S.A. and Marvin, W.C., "A Method of Simulating the Performance of a Pabble Bed Thermal Energy Storage and Recovery Systems", ASME Paper 76- HT-73, ASME/AIChE National Heat Transfer Conference, St. Louis, August 1976.

[12] Schumann, T.E.W., "Heat transfer: Liquid flowing through a porous prism", Franklinelnst, Vol. 208, 405-4 16, 1929.

[13] Standish, N. and Drinkwater, J.B., "The Effect of Particle Shape on Flooding Rates in Packed Columns", Chemical Engg. Science, Vol. 25, 1619-1621, 1970.

[14] Sukhatme, S.P., "Solar Energy-Principles of Thermal Collection and Storage", Tata McGraw Hill Co. Ltd., N. Delhi, 2001

[15] Singh, Ranjit, R.P. Saini, J.S. Saini;"Nusselt number and friction factor correlations for packed bed solar energy storage system having large sized elements of different shapes"Solar Energy, Volume 80, Issue 7, Pages 760-771,July 2006. 